\title{
What Fills the Gaps Left by Employer-Provided Insurance?
}

\author{
Thomas G. Koch
}

Published online: 3 June 2009

(C) The Author(s) 2009. This article is published with open access at Springerlink.com

\begin{abstract}
Employer-provided insurance is the leading source of medical insurance for non-elderly Americans. However, it leaves many without coverage. Evidence suggests that the non-group insurance market does a poor job of filling in these gaps, for those with both short- and long-term uninsurance. It does so for all income and age groups, as well as for both genders. It does fill some of the gaps in employer-provided coverage for those with middle and high incomes, though very incompletely.
\end{abstract}

Keywords Employer-provided insurance • Partial insurance

JEL Classification I 1 J7

\section{Introduction}

Employers are the leading providers of insurance for non-elderly Americans. Thanks to preferential tax treatment, the medical insurance-as-compensation paradigm ties medical insurance to employment status. The irregular nature of employment drives the potential for spells of uninsurance that coincide with spells of unemployment. While laws such as COBRA expand the availability of employer-provided insurance beyond the last date of employment, they do so at a high cost to the (former) worker. It has also been noted that the employer provision of insurance may lead workers to stay on the job too long. Madrian

T. G. Koch (凶)

University of California Santa Barbara, 2127 North Hall,

Santa Barbara, CA 93106, USA

e-mail: koch@econ.ucsb.edu 
(1994) finds evidence that sick workers stay on jobs inefficiently for access to group insurance provided by the job.

Either inefficient outcome (not enough insurance, too much employment) depends upon the irregular nature of the labor market, and the possibility of (suitably substitutable) medical insurance outside of it. Standard assumptions about risk aversion yield a strong result—agents should demand full insurance if a competitive market with full information is able to provide it at an actuarially fair price. Deviations from fully symmetric information may lead to adverse selection and market failure, such as in Rothschild and Stiglitz (1976) and Akerlof (1970). Thus, non-group insurance markets, without the restrictions of the employer-provided market, should be able to provide insurance for the gaps left by employer-provided insurance, and perhaps even do a better job.

In order to assess the adequacy of non-employer medical insurance as a replacement for employer-provided insurance, the patterns of irregular employer-provided insurance are connected to periods of other medical insurance. Detailed insurance data is available in the Medical Expenditure Panel Survey (MEPS), which reports insurance status on a month-by-month basis, by source. While non-group insurance does fill in some of the gaps left by employer-provided insurance, it does a very incomplete job. Breaking down these gaps by demographics, health and income shows that the non-group market is failing to fill in the gaps for all groups.

These finding are consistent with earlier research. The irregular nature of insurance, and the difficulty of measuring this in typical survey data has been discussed in Lewis et al. (1998). The difference between point-in-time measurements, and the "have you had insurance at all recently" questions asked by typical surveys, has been investigated by Swartz (1994). More recent studies of Olson et al. (2005) and Short and Graefe (2003) follow up that work. That literature reports the differences between the point-in-time realities faced by households, and the answers households provide when asked more general survey questions. In this study, these patterns are broken down by insurance sources, and according to relevant health, demographic and income variables to understand the capacity for non-group insurance to temporarily fill in for employer-provided insurance.

These gaps have consequences for health care access and health care utilization. Leininger (2009) found that gaps in coverage have significant effects for total utilization. Thus, individuals cannot just intertemporally substitute their way out of a gap in insurance coverage - the gaps left unfilled by employer provided insurance matter. Thus, it is important to understand for whom nongroup insurance fails (or succeeds) to fill these gaps.

\section{Irregular Insurance is Employer-(not) Provided}

The sources and spans of insurance are found in the 2006 Medical Expenditure Panel Survey (MEPS). The MEPS collects data on health care utilization and 
its sources, insurance and its source, labor market outcomes, and demographics for a nationally-representative sample of the US. Respondents provide data five times over a two year panel. The data include precise information regarding the timing and source of insurance, through its monthly insurance status variables. For each month of 2006, it is determined whether an individual has any medical insurance; whether that insurance is public or private; and if private, whether it is employer-provided, other group, or non-group. Because they represent the predominant sources of private insurance,the first and the last types of insurance are the subjects of interest. From this information, the number of months insured by a source of insurance are constructed. If an individual has insurance from a source the entire year, the person is continuously insured; if there is some coverage, but not for the entire year, the person is irregularly insured. The rest are not insured by a source.

Table 1 presents the sample means of standard socio-economic and demographic variables for the data. Four main variables are of interest are reported-age, gender, self-reported health status and family income as a fraction of the poverty level. Self-reported health status is asked of the family's respondent at the time of the second interview in a calendar year (the second interview in the first year, or the fourth in the second year). Responses of "excellent," "very good," or "good," are recoded as "good", while responses of "fair" or "poor" are recoded as "not good." Nearly $91 \%$ of the sample reported being in "good health."

Family income information is collected throughout the MEPS sampling periods, and used to construct the family's income as a fraction of the federal poverty line. Households with income less than $200 \%$ of the poverty line (roughly $\$ 40,000$ for a family of four) were classified as "low income or below," while the rest were "middle income or above." Nearly $70 \%$ of the households were recorded as earning middle income or greater.

Table 2 presents the fraction of the population that reported each number of months of insurance, from a source. These fractions are from the the non-elderly, non-Veteran sub-population. First note that the fraction of the subpopulation with irregular insurance is large, just $2 \%$ smaller than those without insurance the entire year. This is made up primarily of persons with more rather than less insurance-while the irregularly insured are distributed smoothly across one to eleven months, it is more likely that they have one to four months of gaps, compared to eight to eleven months. These measures highlight the advantages of the MEPS, and why it is needed to understand how well non-group insurance fills in the gaps of employer-provided insurance.

Table 1 Sample means for the 2006 MEPS, non-elderly and non-Veteran, using sample weights

$N=27,465$

\begin{tabular}{lc}
\hline Variable & Mean \\
\hline Age & 30.8 \\
1==Male & 0.477 \\
"Good health" & 0.919 \\
Inc. > $2 x F P L$ & 0.698 \\
\hline
\end{tabular}


Table 2 Number of months insured, non-elderly and non-Veteran populations

$N=27,498$

\begin{tabular}{lllll}
\hline Months & Any & Private & Employer-provided & Non-group \\
\hline 0 & 0.142 & 0.306 & 0.361 & 0.972 \\
1 & 0.004 & 0.004 & 0.004 & 0.001 \\
2 & 0.008 & 0.005 & 0.005 & 0.001 \\
3 & 0.008 & 0.006 & 0.006 & 0.001 \\
4 & 0.011 & 0.009 & 0.009 & 0.001 \\
5 & 0.012 & 0.010 & 0.009 & 0.001 \\
6 & 0.010 & 0.008 & 0.009 & 0.002 \\
7 & 0.013 & 0.009 & 0.008 & 0.001 \\
8 & 0.015 & 0.009 & 0.009 & 0.001 \\
9 & 0.015 & 0.010 & 0.009 & 0.001 \\
10 & 0.016 & 0.012 & 0.011 & 0.001 \\
11 & 0.015 & 0.010 & 0.009 & 0.001 \\
12 & 0.736 & 0.605 & 0.552 & 0.018 \\
\hline
\end{tabular}

These gaps overall can be tied directly to gaps in the private insurance market. And gaps in the private insurance market are due to gaps in employerprovided insurance. The third column of Table 2 presents the fraction of the population with employer-provided insurance for some number of months, while the fourth presents the same for non-group insurance. The non-group insurance market is much smaller than the employer-provided market. The fraction with some non-group insurance is large relative to those with an entire year's worth of non-group insurance, vis-a-vis employer-provided insurance, if only because the former market is so small. This, in turn, mitigates its capacity to fill in the gaps left by employer-provided insurance.

Reading these gaps is a delicate craft. While it currently appears that the non-group market is not filling the gaps left by the employer-provided market, it just states that the reverse of Say's Law (i.e., demand creates its own supply) does not hold locally. ${ }^{1}$ This does not speak to the welfare consequences if the tax incentives for employer-provided insurance were removed, and the employer-provided market were replaced by the non-group market. The local market failure on display here may be reproduced en masse in such a counterfactual policy experiment, or it may not. These summary statistics suggest private non-group insurance markets do an incomplete job of filling in the gaps that currently exist.

One final point about these gaps-they may be due to unemployment, employers not offering insurance, or workers not enrolling in insurance plans. Sommers and Crimmel (2008) use related information in the 2006 MEPS, and find that $87 \%$ of US private-sector workers have employers that offer insurance, and that only $61 \%$ of them ultimately enroll. In either case, workers (and their dependents) have legitimate demand for medical insurance, and may remain uninsured.

\footnotetext{
${ }^{1}$ If there are competitive insurance markets with no or small loading costs, risk aversion guarantees that all agents will demand (and be supplied with) full insurance at an actuarially fair price.
} 


\section{Breaking Down the Gaps}

One concern about non-group insurance's ability to substitute for employerprovided insurance is its affordability. This question has previously been addressed by Bundorf and Pauly (2006), which also looked at the MEPS, though using a broader measure of insurance. Following their lead, these trends are broken down by poverty category, as reported by the MEPS. If the relationship between gaps in employer-provided insurance and spans of nongroup insurance grow stronger as people grow wealthier, affordability may be an issue.

Table 3 presents the fractions of the population with insurance by length of coverage, broken down by insurance type, and split between those with middle income or above, or below. Unsurprisingly, lower-income families have members who are much less likely to have insurance. This is in part because lower-income families may not have access to employer-provided insurance, because of unemployment, or employers won't offer it to lower-wage workers. The public medical insurance safety net provided by Medicaid and SCHIP mitigates the lack of insurance. However, the non-group insurance market does very little to fill in the gaps.

Why might this be the case? Typical assumptions about preferences, such as constant relative risk aversion, induce higher demand for insurance among lower income risk avoiders. Bundorf and Pauly (2006) finds that using the classical sense of affordability ("Is it in the budget set?"), income constraints are not an issue for many of these low-income families. If health care is a normal good, and medical insurance contracts are not sensitive to these differences, they may be selected out of the insurance market.

Another key feature of employer-provided insurance is that it does not discriminate. Or, rather, it is not allowed to discriminate in price in ways that an actuarially fairly priced insurance contracts would discriminate. Employers are forbidden from varying employee contributions according to gender, age, or health status. Yet actuarially fair non-group insurance contracts would, depending upon state regulations. For example, Codispoti et al. (2008) documented the different prices women face for medical insurance in the non-group market.

While women may face different prices, there is not much evidence that the non-group market works any better or worse for women than it does for men.

Table 3 Number of months insured, non-elderly and non-Veteran populations, by poverty group

\begin{tabular}{|c|c|c|c|c|c|c|c|c|}
\hline \multirow[t]{2}{*}{ Months } & \multicolumn{4}{|c|}{ Family income $<200 \%$ of FPL $(0.302)$} & \multicolumn{4}{|c|}{$\geq 200 \% F P L$} \\
\hline & Any & Private & E-P & $\mathrm{N}-\mathrm{G}$ & Any & Private & E-P & $\mathrm{N}-\mathrm{G}$ \\
\hline 0 & 0.239 & 0.659 & 0.712 & 0.978 & 0.100 & 0.154 & 0.209 & 0.969 \\
\hline $1-11$ & 0.186 & 0.097 & 0.089 & 0.009 & 0.094 & 0.085 & 0.087 & 0.011 \\
\hline 12 & 0.575 & 0.245 & 0.199 & 0.014 & 0.806 & 0.761 & 0.705 & 0.020 \\
\hline
\end{tabular}

$N=27,498$ 
Table 4 Number of months insured, non-elderly and non-Veteran populations, by gender

\begin{tabular}{|c|c|c|c|c|c|c|c|c|}
\hline \multirow[t]{2}{*}{ Months } & \multicolumn{4}{|c|}{ Male (0.477) } & \multicolumn{4}{|c|}{ Female } \\
\hline & Any & Private & E-P & $\mathrm{N}-\mathrm{G}$ & Any & Private & E-P & $\mathrm{N}-\mathrm{G}$ \\
\hline 0 & 0.166 & 0.315 & 0.367 & 0.973 & 0.120 & 0.298 & 0.354 & 0.970 \\
\hline $1-11$ & 0.119 & 0.089 & 0.088 & 0.011 & 0.124 & 0.088 & 0.087 & 0.010 \\
\hline 12 & 0.715 & 0.596 & 0.545 & 0.016 & 0.756 & 0.613 & 0.559 & 0.020 \\
\hline
\end{tabular}

$N=27,498$

Table 4 breaks down the incidence of full, irregular and no insurance by source and gender. Women are generally more likely to be insured, but this is not due to increased incidence of non-group insurance (or in spite of a decreased incidence of it). The fraction of women irregularly insured is the same as that for men; the increased incidence of continuous insurance for women is drawn from the decreased incidence of a continuous lack of insurance among women.

It can also be useful to break down insurance rates by self-reported health. While this is a subjective measure of an individual's health, it might provide insight as to how the market fills in the gaps for those who are subject to a selfperceived demand shifter of health insurance. These responses are recoded as "good health" or "not good health" as described above, and the insurance rates were broken by these health categories. The statistics are reported in Table 5.

The healthy are more likely to have insurance, especially employerprovided insurance. Both groups have a similar incidence of irregular insurance, though neither group is often served by the non-group insurance market. Of course, the causation here is not clear-the unhealthy could not have insurance because they cannot work, or the limited access to care of the uninsured drives the uninsured to be less healthy.

Age is another piece of information that private markets would use in a non-group setting, but employers are restricted from using. The expansions of public health insurance in the late 1990s and early 2000s make it essential to consider two distinct groups-children under age 18, and adults 19 and older. These expansions were focused on children (hence the State Children's Health Insurance Program), and primarily increased the family income eligibility thresholds.

Table 6 presents the incidence of private insurance among children, according to family income relative to $200 \%$ of the federal poverty line. Children from

Table 5 Number of months insured, non-elderly and non-Veteran populations, by self-reported health status

\begin{tabular}{|c|c|c|c|c|c|c|c|c|}
\hline \multirow[t]{2}{*}{ Months } & \multicolumn{4}{|c|}{ Healthy (0.919) } & \multicolumn{4}{|c|}{ Unhealthy } \\
\hline & Any & Private & E-P & $\mathrm{N}-\mathrm{G}$ & Any & Private & E-P & $\mathrm{N}-\mathrm{G}$ \\
\hline 0 & 0.138 & 0.288 & 0.343 & 0.971 & 0.191 & 0.509 & 0.555 & 0.979 \\
\hline $1-11$ & 0.119 & 0.089 & 0.088 & 0.011 & 0.153 & 0.089 & 0.080 & 0.007 \\
\hline 12 & 0.743 & 0.623 & 0.569 & 0.019 & 0.656 & 0.402 & 0.364 & 0.013 \\
\hline
\end{tabular}

$N=27,465$ 
Table 6 Number of months insured, children, by family income group

\begin{tabular}{|c|c|c|c|c|c|c|c|c|}
\hline \multirow[t]{2}{*}{ Months } & \multicolumn{4}{|c|}{ Family income $>200 \% \mathrm{FPL}$} & \multicolumn{4}{|c|}{$<200 \%(0.385)$} \\
\hline & $\overline{\text { Any }}$ & Private & E-P & $\mathrm{N}-\mathrm{G}$ & $\overline{\text { Any }}$ & Private & E-P & $\mathrm{N}-\mathrm{G}$ \\
\hline 0 & 0.053 & 0.162 & 0.224 & 0.975 & 0.077 & 0.721 & 0.759 & 0.986 \\
\hline $1-11$ & 0.089 & 0.073 & 0.069 & 0.010 & 0.174 & 0.067 & 0.063 & 0.006 \\
\hline 12 & 0.858 & 0.765 & 0.708 & 0.015 & 0.749 & 0.212 & 0.179 & 0.009 \\
\hline
\end{tabular}

$N=9,879$.

low-income (and below) families are more likely to lack continuous insurance, and particularly more likely to be irreguarly insured. These differences are due overwhelmingly to the lack of regular employer-provided insurance. This private insurance may be "crowded out" by the public insurance available to these children. In either case, non-group insurance does not fill in the gaps left by either irregular employer-provided plans, or employer-provided and public insurance plans.

Among the adults, consider two age groups-the young (19-55) and near elderly (55-64). Insurance incidence rates broken down by these two age groups are reported in Table 7. Both groups exhibit a large portion without insurance, though the near-elderly are more likely to have employer-provided insurance. The role of non-group insurance in either group is limited. It does not provide more insurance to the younger group, in spite of the greater incidence of uninsurance in that group. Nor does it provide much insurance to the near-elderly, in spite of the fact that the elderly likely have larger certainty equivalents (willingness to pay for insurance less expected cost), and would be more willing to take on the loading costs of insurance.

A linear probability model of ever having non-group insurance is used to control for the many ways in which these groups differ that might confound the differential incidence according to gender, income, etc. The explanatory variables include the demographic and health information used abovegender, income level, age group and self-reported health status. Two indicator variables are also used-whether the individual had one to 11 months of employer-provided insurance during the period, or if they did not have any. This provides a sense of how often non-group insurance fills in for gaps in employer-provided insurance, allowing for a qualitative difference between some, but incomplete employer-provided insurance in a year, and a complete lack of employer-provided insurance during a year.

Table 7 Number of months insured, non-elderly and non-Veteran adult populations, by age group

\begin{tabular}{|c|c|c|c|c|c|c|c|c|}
\hline \multirow[t]{2}{*}{ Months } & \multicolumn{4}{|c|}{ Young $(0.841)$} & \multicolumn{4}{|c|}{ Near-elderly } \\
\hline & Any & Private & E-P & $\mathrm{N}-\mathrm{G}$ & Any & Private & E-P & $\mathrm{N}-\mathrm{G}$ \\
\hline 0 & 0.189 & 0.284 & 0.338 & 0.971 & 0.120 & 0.225 & 0.290 & 0.956 \\
\hline $1-11$ & 0.131 & 0.104 & 0.104 & 0.012 & 0.070 & 0.057 & 0.056 & 0.009 \\
\hline 12 & 0.680 & 0.611 & 0.558 & 0.018 & 0.811 & 0.719 & 0.654 & 0.035 \\
\hline
\end{tabular}

$N=17,619$ 
The equation of interest is:

$$
N G \operatorname{Ins}_{i}=\beta_{1} \cdot \operatorname{NoEP}_{i}+\beta_{2} \cdot \text { Some } E P_{i}+\beta_{X} \cdot X+\epsilon_{i},
$$

where $X$ is a matrix of the categorical demographic and health variables, and $N o E P_{i}$ and Some $E P_{i}$ are the employer-provided insurance explanatory variables. Since all of the explanatory variables are categorical variables (and no constant term is added), the usual concerns about the linear probability model (e.g., predicted values below zero or above one) do not apply. The linear probability model with categorical explanatory variables creates a multivariate cross tabulation, with the coefficients representing the cell differences across the cross-tabulated characteristics.

Table 8 reports the coefficients for no employer-provided insurance and irregular employer-provided insurance. It suggests that non-group insurance does fill in for gaps in the employer-provided insurance market. The effects are small, and the relative magnitudes are intuitive - those who do not have any employer-provided insurance during the year are more likely to have some non-group insurance. That said, the economic significance of these effects are small - the gaps in employer-provided coverage are large, and in theory should

Table 8 Selected estimated coefficients from a linear probability model of having any non-group insurance

\begin{tabular}{lccc}
\hline & $(1)$ & $(2)$ & $(3)$ \\
\hline NoEP & $0.066^{* * *}$ & -0.014 & -0.007 \\
SomeEP & $(0.005)$ & $(0.009)$ & $(0.008)$ \\
& $0.063^{* * *}$ & 0.020 & 0.018 \\
NoEP*Female & $(0.009)$ & $(0.023)$ & $(0.024)$ \\
SomeEP*Female & 0.017 & 0.016 \\
& & $(0.007)$ & $(0.007)$ \\
NoEP*Healthy & -0.006 & -0.006 \\
& $(0.015)$ & 0.015 \\
SomeEP*Healthy & $0.035^{* * *}$ & $0.032^{* * *}$ \\
& & $(0.008)$ & $(0.008)$ \\
NoEP*Old & 0.027 & 0.028 \\
& & $(0.019)$ & $(0.019)$ \\
SomeEP*Old & $0.052^{* * *}$ & 0.005 \\
& $(0.016)$ & $(0.019)$ \\
NoEP*(>200\%FPL) & -0.017 & -0.003 \\
& $(0.025)$ & $(0.040)$ \\
SomeEP*(>200\%FPL) & $0.081^{* * *}$ & $0.069^{* * *}$ \\
& & $(0.011)$ & $(0.011)$ \\
NoEP*(>200\%FPL)*Old & 0.039 & 0.041 \\
& & $(0.017)$ & $(0.017)$ \\
SomeEP*(>200\%FPL)*Old & & $0.089^{* * *}$ \\
$N=17,598$ & & $(0.033)$ \\
& & & $(0.023$ \\
& & & \\
\hline
\end{tabular}

***, ed coefficients are statistically different from zero at $99 \%$. 
be filled by non-group insurance. However, as the previous tables indicated, they are not.

Which gaps are filled? In order to assess this, these two measures of irregular employer-provided insurance are interacted with the four covariates of interest-age group, gender, income and self-reported health. Non-group insurance fills the large gaps of employer-provided insurance for households with middle and high incomes-those with the greatest ability to pay for nongroup insurance. However, there is no effect when there is some employerprovided insurance during the year. The near-elderly and healthy are likely to have non-group insurance, but, again, only those who lack employer-provided insurance for the entire year. Other interactions are neither statistically nor economically significant, suggesting that the failure of non-group insurance to fill in the gaps is due more to income than other observable characteristics.

The effects of income and age may mix, as the two are correlated. Do they reinforce one another? To test this, the near-elderly dummy is interacted with the middle-income or higher dummy. As before, the near-elderly with more income are not more likely to have non-group insurance if they are partially insured through an employer plan. However, they are more likely to have non-group insurance if they do not have employer-provided insurance. The role of income is particularly important for the near elderly-note that the coefficient for the low-income and below near elderly falls to near zero with no statistical significance. They are not likely to have non-group insurance if they lack employer-provided insurance. However, the middle-income and higher near-elderly do get insurance, at twice the rate of the young in the same income group.

\section{Conclusion}

Employer-provided medical insurance is the primary source of medical insurance for non-elderly Americans. Irregular employment can lead to irregular medical insurance, if non-group insurance does not fill in the gaps. There is evidence that while non-group insurance does fill in some of the gaps left by employer-provided insurance, it still leaves many gaping holes in coverage. While incidence of non-group insurance does vary by income, age, health status and gender (by varying degrees), it by no means fills in the gaps completely.

These results should be troubling to both economic theorists and those who prescribe policy. Economic theory suggests that insurance markets will work best when information is used freely and symmetrically, and without the many restrictions on insurance provided at the workplace. The failure of non-group insurance to fill in the gaps left by employer-provided insurance suggests that just because a market should work does not mean that it will. 
Open Access This article is distributed under the terms of the Creative Commons Attribution Noncommercial License which permits any noncommercial use, distribution, and reproduction in any medium, provided the original author(s) and source are credited.

\section{References}

Akerlof GA (1970) The market for 'Lemons': quality uncertainty and the market mechanism. Q J Econ 84(3):488-500

Bundorf MK, Pauly MV (2006) Is health insurance affordable for the uninsured? J Health Econ 25(4):650-673

Codispoti L, Courtot B, Swedish J (2008) Nowhere to turn: how the individual health insurance market fails women. Technical Report, National Women's Law Center

Leininger LJ (2009) Partial-year insurance coverage and the health care utilization of children. Med Care Res Rev 66(1):49-67

Lewis K, Ellwood M, Czajka JL (1998) Counting the uninsured: a review of the literature. Occasional Paper 8, Urban Institute, Washington, DC

Madrian BC (1994) Employment-based health insurance and job mobility: is there evidence of job-lock? Q J Econ 109(1):27-54

Olson LM, Tang SFS, Newacheck PW (2005) Children in the United States with discontinuous health insurance coverage. N Engl J Med 353(4):382-391

Rothschild M, Stiglitz JE (1976) Equilibrium in competitive insurance markets: an essay on the economics of imperfect information. Q J Econ 90(4):630-49

Short PF, Graefe DR (2003) Battery-powered health insurance? Stability in coverage Of the uninsured. Health Aff 22(6):244-255

Swartz K (1994) Dynamics of people without health insurance: don't let the numbers fool you. JAMA J Am Med Assoc 271(1):64-66

Sommers J, Crimmel BL (2008) Offer rates, take-up rates, premiums, and employee contributions for employer-sponsored health insurance in the private sector for the 10 largest metropolitan areas, 2006. Statistical Brief 210, Agency for Healthcare Research and Quality, Rockville 